\title{
WATER-PRESSURE COUPLING OF SLIDING AND BED DEFORMATION: III. APPLICATION TO ICE STREAM B, ANTARCTICA
}

By R.B. Alley, D.D. Blankenship, S.T. Rooney, and C.R. Bentley

(Geophysical and Polar Research Center, University of Wisconsin-Madison, Madison,

Wisconsin 53706-1692, U.S.A.)

ABSTRACT. Geophysical studies and glaciological analyses suggest strongly that Ice Stream B, West Antarctica, moves primarily by pervasive deformation of a meters thick subglacial till. Analysis of the longitudinal profile of the ice stream up-stream of the ice plain suggests that basal sliding is slow everywhere, that effective pressure decreases slowly down-stream, and that the strain-rate of pervasive shear is proportional to the basal shear stress and inversely proportional to the square or cube of the effective pressure Discrete shearing may occur beneath the pervasively deforming zone. These and other hypotheses, which build on the analyses of the first two papers in this series, can be tested in the field.

\section{INTRODUCTION}

The dynamics and stability of the West Antarctic ice sheet are fundamental problems in glaciology, and clearly are related to the behavior of the fast-moving ice streams that drain the ice sheet. Much effort has been devoted to modeling Ice Streams $\mathrm{A}-\mathrm{F}$ on the Siple Coast of West Antarctica (see review in Bentley (1987)), and the resulting models have contributed significantly to our understanding of the system. However, all models prior to 1987 that considered the entire longitudinal profile of the ice streams required the use of ad hoc sliding laws or tuning parameters to approximate modern behavior. This is because the ice-stream velocity generally increases down-stream but the basal shear stress decreases down-stream, and the modeled down-stream increase in a lubricating water film does not seem sufficient to explain this behavior within the confines of physically based sliding laws.

We recently have presented data (e.g. Blankenship and others, 1986, 1987; Rooney and others, 1987b) and analyses (e.g. Alley and others, 1986, 1987a, b, c) suggesting that Ice Stream B moves primarily by pervasive deformation of a meters thick subglacial till, and that this may. explain the enigmatic behavior of the ice stream. In particular, we developed a flow model with a deforming bed that explained all of the available data (Alley and others, 1987c). To do so, however, we were forced to tune the assumed viscosity of the till to reproduce the modern ice-stream profile. Although the trend in viscosity resulting from this exercise matched the expected trend, this is something of an ad hoc solution.

Unfortunately, despite the signal work of Clarke (1987), current understanding of till deformation is not sufficiently advanced to allow confident prediction of viscosities from first principles. The empirical studies of

\footnotetext{
* Present address: Earth System Science Center and Department of Geosciences, The Pennsylvania State University, University Park, Pennsylvania 16802, U.S.A.
}

Boulton and Hindmarsh (1987) provide the best available flow law for subglacial till deformation.

In part I of this series (Alley, 1989a) we clarified the terminology we use for glaciers with deforming beds, and in parts I and II (Alley, 1989a, b) we extended the theoretical framework for interpreting the behavior of such glaciers. Here we investigate whether a flow law of the type used by Boulton and Hindmarsh (1987) can predict (or at least explain) the viscosity variations needed to model Ice Stream B.

We first examine the longitudinal profile of the ice stream. The variation of velocity and shear stress along flow depend on the basal conditions, so observed values serve to constrain possible models of bed behavior. We then discuss likely variation of till velocity with depth. The result is a series of hypotheses that can be tested by further field studies and that can be used in modeling exercises until better data are available.

\section{LONGITUDINAL PROFILE}

\section{Physical setting}

Recent research by participants in the Siple Coast Project has produced exciting new glaciological data from Ice Stream B and its surroundings (e.g. Bentley, 1987; Bentley and others, 1987; Bindschadler and others, 1987; MacAyeal and others, 1987; Shabtaie and Bentley, 1987; Shabtaie and others, 1987; Whillans and others, 1987; Alley and Bentley, 1988; see part I, fig. 1). The ice stream carries the accumulation of a large section of West Antarctica across the Siple Coast and into the Ross Ice Shelf. It is recognizable for about $400 \mathrm{~km}$ along flow, but the last $100 \mathrm{~km}$ are an "ice plain" with very low, almost ice-shelflike surface slopes. In the upper $150 \mathrm{~km}$ the ice stream has two main branches separated by a slower-moving ridge, but ice from the branches is distinct down-stream of their junction. The entire drainage system of Ice Stream B shows a significantly negative mass balance, probably attributable in large part to thinning associated with headward growth of the ice stream into its catchment area. Ice velocities are high $\left(\approx 500 \mathrm{~m} \mathrm{a}^{-1}\right)$ despite low driving stresses $(\approx 20 \mathrm{kPa})$; ice thicknesses are near $1000 \mathrm{~m}$, and the bed is roughly horizontal along flow. Accumulation rates on the ice stream and in much of its catchment area are low $(\approx 100 \mathrm{~mm}$ ice $\left.\mathrm{a}^{-1}\right)$. Temperatures are low $\left(\approx-26^{\circ} \mathrm{C}\right)$, surface melt is rare, and no run-off occurs.

Much information also has been obtained about the geological setting of Ice Stream B. The ice stream generally follows the axis of a subglacial trough tens to hundreds of meters deep, although exact correspondence is not maintained between the margins of the trough and the ice stream (Shabtaie and others, 1987). The trough probably is structurally controlled but modified by glacial erosion (Rooney and others, 1987a, b). Beneath the meters thick subglacial till, the ice stream is underlain by hundreds of 
meters of sedimentary rocks with low seismic velocities; based on available geological data and analogy to geophysical properties of sediments beneath the Ross Sea, these probably are poorly indurated, Neogene glaciomarine sediments (Rooney and others, 1989).

One of the more exciting results of the Siple Coast Project has been the discovery of a subglacial substrate that on the basis of geophysical evidence is probably a meters thick, unconsolidated layer beneath the ice stream near the Upstream B camp (UpB; see part I, fig. 1), characterized by high porosity and high pore-water pressure (Blankenship and others, 1986, 1987; Rooney and others, 1987b). The layer is known to occur over a $10 \mathrm{~km}$ by $10 \mathrm{~km}$ area near UpB (Rooney and others, 1988); preliminary interpretation of seismic data collected near the Downstream B camp (DnB, part I, fig. 1) about $200 \mathrm{~km}$ down-stream, suggests that the same layer occurs there with similar thickness (Blankenship and others, 1989). We have argued that this layer probably is deforming pervasively beneath the ice stream and causing most of the ice velocity (Alley and others, $1986,1987 \mathrm{a}, \mathrm{b}, \mathrm{c}$ ).

This layer is similar, in thickness and stratigraphic relation to other units, to the widespread till overlying the Ross Sea unconformity beneath the Ross Sea (Barrett, 1975; Anderson and others, 1980; Karl and others, 1987). This similarity, plus our hypotheses about till deformation and its effect on ice-sheet history, have led us to suggest that the layer beneath Ice Stream B and the Ross Sea till had the same origin, that the Ross Sea till records Wisconsinan icestream flow in an expanded ice sheet, and that the layer beneath Ice Stream B is a till like that in the Ross Sea (Alley and others, 1989).

The amount of detailed data available regarding Ice Stream B exceeds our present capability to understand or model it (although MacAyeal (in press), Whillans and Van der Veen (1989), and others are making excellent progress). To isolate the effects of basal processes, it is convenient to simplify the system drastically.

We thus consider the idealized, two-dimensional, steady ice stream shown in Figure 1 , from Alley and others $(1987 \mathrm{c})$. The head of this idealized ice stream is at $x=0$,

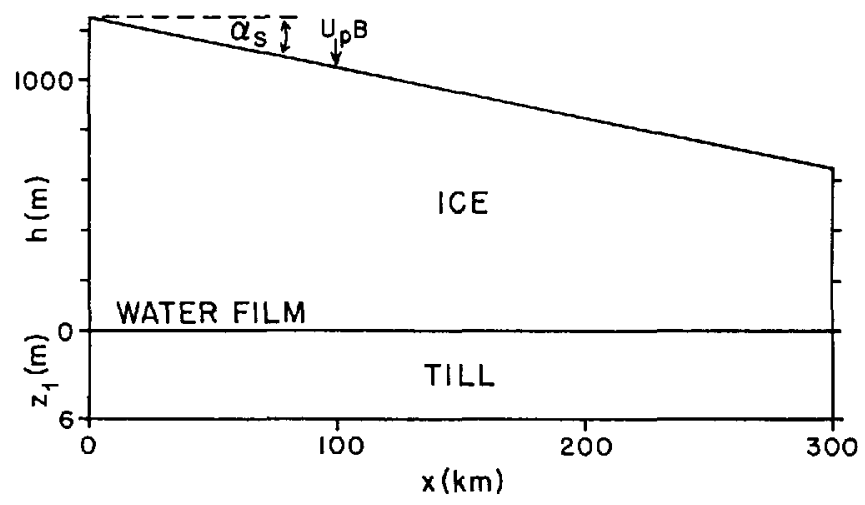

Fig, 1. Smoothed, two-dimensional version of Ice Stream B used in model calculations. Modified from Alley and others $(1987 \mathrm{c})$.

and the coupling line between the main part of the ice stream and the ice plain is at $x=300 \mathrm{~km}$; we defer the problem of flow beyond the coupling line to a later study. Surface slope is constant at $\alpha_{s}=0.002$, bed slope is constant at $\alpha_{b}=0$, and accumulation rate is constant at $\dot{b}=0.1 \mathrm{ma}^{-1}$ of ice. The UpB camp is at $x=100 \mathrm{~km}$, where the ice thickness is $h=1050 \mathrm{~m}$, the ice velocity is $u_{\mathrm{iB}}=448 \mathrm{~m} \mathrm{a}^{-1}$ and the deforming till thickness is $z_{1}=6 \mathrm{~m}$. Velocity from internal ice deformation is assumed to be negligible, and the driving stress is assumed to be balanced by the basal shear stress. From this, we can calculate the basal velocity and basal shear stress everywhere along the model ice stream (Alley and others, 1987c; aiso Fig. 2). The preliminary observations of Blankenship and others (1989) and the model results of Alley and others (1987c) suggest that till thickness does not vary rapidly
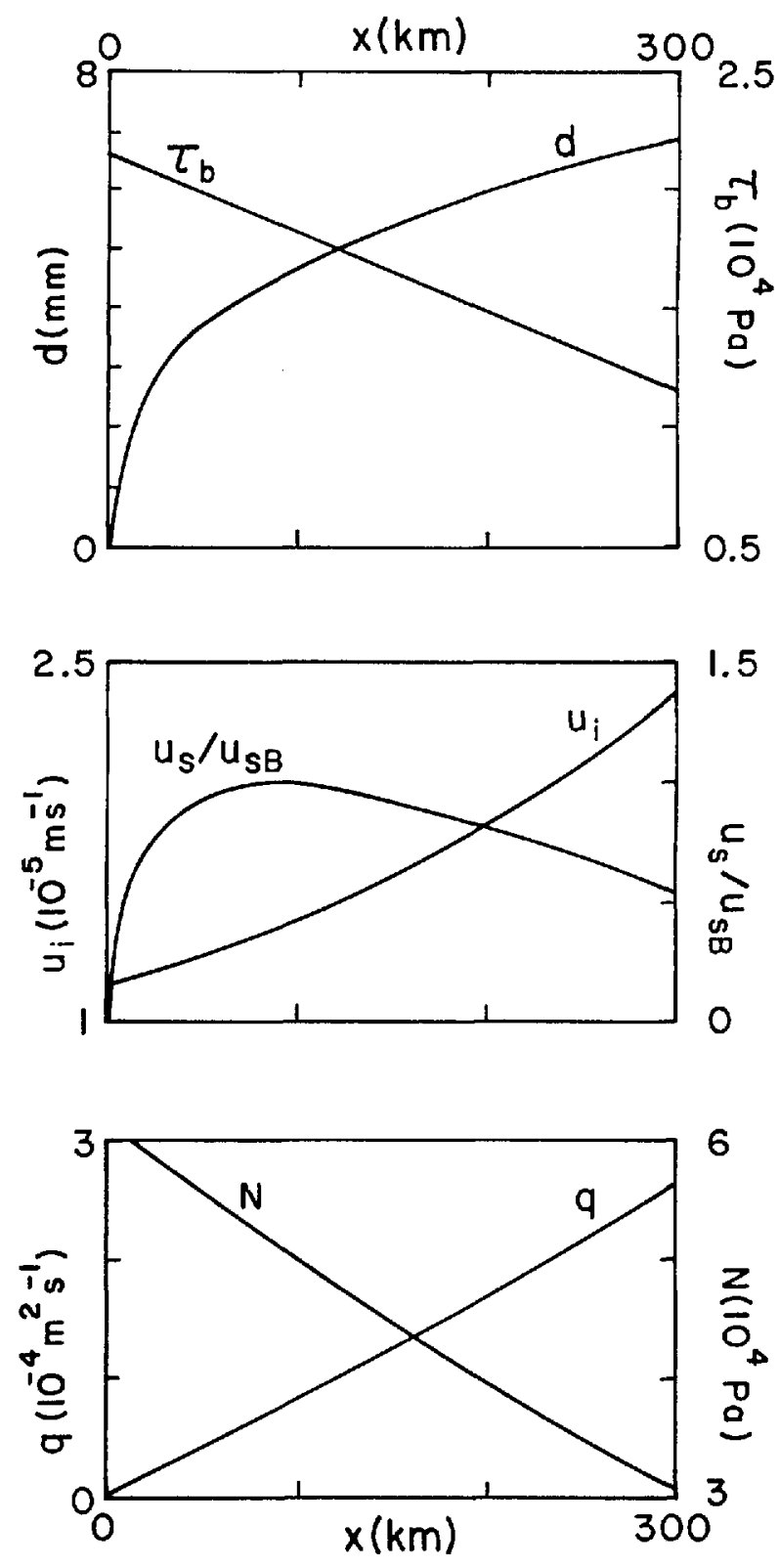

Fig. 2. Calculated values of important variables along model ice stream in Figure 2. The head of the ice stream is at $x=0 \mathrm{~km}$ and $U p B$ is at $x=100 \mathrm{~km}$. $\tau_{b}=$ basal shear stress, $d=$ water-film thickness, $u_{1}=$ ice velocity, $u_{s} / u_{s \mathrm{~B}}=$ ratio of sliding velocity $\left(u_{s}\right)$ to sliding velocity at $U p B\left(u_{s \mathrm{~B}}\right), q=$ water flux at ice-till interface, and $N=$ effective pressure.

along flow, so we assume $z_{1}=6 \mathrm{~m}$ to apply to the entire length. The effect of probable errors in these assumptions is discussed in the sub-section on sensitivity, below, and in Alley and others (1987c).

As noted above, it is likely that the layer beneath Ice Stream B is a till similar to that observed in the Ross Sea (Alley and others, 1989). A reasonable approximation to the measured grain-size distribution of that material (Barrett, 1975; Anderson and others, 1980) is that clasts fall into seven size classes with radii $R_{j}=10^{-6}, 10^{-5}, \ldots, 10^{0} \mathrm{~m}$ with one-tenth of the volume in each of the seven size classes and with the remaining $30 \%$ of the volume assumed to be in pores (cf. Boulton and Hindmarsh, 1987). This probably overestimates the volume fraction in the two coarsest classes, but is convenient and is not a bad approximation. Seismic measurements on Ice Stream B show that roughness elements at the $10 \mathrm{~m}$ vertical scale are absent or scarce, especially parallel to flow (Rooney and others, 1987b). We initially assume that this subglacial till rests directly on rigid bedrock, although later we relax this assumption somewhat. 


\section{Water system}

Calculations for Ice Stream B show that it generates much more water than could be conducted through likely subglacial aquifers (Lingle and Brown, 1987) or advected in a deforming bed (Alley and others, 1987b), so drainage must occur at the ice-bed interface. As discussed in part I, such drainage over an unconsolidated bed beneath a cold glacier is likely to occur in an inefficient, distributed system with an effective pressure of only $0\left(10^{4} \mathrm{~Pa}\right)$. Although this water system is likely to evolve rapidly, with growth and collapse of local thickenings, we hypothesized in part I that it will resemble a perturbed film more than channelized drainage.

We thus choose to model the water flow as occurring through a Weertman film (Weertman, 1972; Weertman and Birchfield, 1982). The thickness, $d$, of such a Weertman film is (see part I, equation (25))

$$
d=\left(\frac{12 \mu q}{P_{\mathrm{g}}}\right]^{1 / 3}
$$

where $\mu=1.8 \times 10^{-3} \mathrm{PaS}$ is the viscosity of water, $q$ is the water flux in $\mathrm{m}^{3} / \mathrm{s}$ per meter width, and $P_{\mathrm{g}}$ is the pressure-gradient driving flow. For the $\mathrm{g}$ assumed configuration of Ice Stream B (see part I, equation (26))

$$
P_{\mathrm{g}}=\rho_{\mathrm{i}} g \alpha_{\mathrm{S}} \approx 18 \mathrm{~Pa} \mathrm{~m}^{-1}
$$

where $\rho_{\mathrm{i}} \approx 910 \mathrm{~kg} \mathrm{~m}^{-3}$ is the ice density, $g=9.8 \mathrm{~m} \mathrm{~s}^{-2}$ is the gravitational acceleration, and $\alpha_{s}=0.002$ is the ice-air surface slope.

The water flux at the ice-bed interface, $q$, is the sum of water entering the head of the ice stream at the ice-bed interface, $q_{\mathrm{i}}$, and the water generated along the ice stream that is not lost to conduction or advection through subglacial aquifers. Model results show that $q_{\mathrm{i}} \ll q$ except possibly in the first tens of kilometers (Budd and Jenssen, 1987), so we take $q_{\mathrm{i}}=0$. Also, water flux from the icebed interface into subglacial aquifers along the ice stream is likely to be small compared to $q$ (Alley and others, 1987b; Lingle and Brown, 1987) so we take it to be zero. Heat conduction through the ice stream is about equal to the geothermal flux (Alley and Bentley, 1988) so $q$ is generated by the heat of sliding.

Basal melting from the heat of sliding occurs at a rate $v_{\mathrm{m}}$ given by

$$
v_{\mathrm{m}}=\frac{u_{\mathrm{i}} \tau_{\mathrm{b}}}{L}
$$

where $u_{\mathrm{i}}$ is the basal ice velocity, $\tau_{\mathrm{b}}$ is the basal shear stress, and $L=3.1 \times 10^{8} \mathrm{~J} \mathrm{~m}^{-3}$ is the heat fusion of ice. Then

$$
q=\int_{0}^{x} v_{\mathrm{m}} \mathrm{d} x
$$

for $q_{\mathrm{i}}=0$. Values of $q$ calculated from Equation (4) are shown in Figure 2. The water-film thickness, $d$, then can be calculated from Equations (1) and (2), and also appears in Figure 2.

In part II (equations (2) and (3)) we discussed the relation between water-film thickness and the fraction of the bed, $f$, occupied by the water film. Equation (3) in part II was derived for the bed roughness that we argue above is most likely to occur beneath Ice Stream B. We thus expect Ice Stream $B$ to be described by

$$
f=1+0.1 \log _{10} d
$$

where $d$ is in meters. In part I we argued that a bed containing abundant roughness elements in a wide range of sizes, such as that assumed here, will have a relation between $f, \tau_{\mathrm{b}}$, and effective pressure $N$ (the difference between the average normal stress of ice on the bed and the water pressure) given by (part I, equation (22))

$$
N=\frac{B T_{\mathrm{b}}}{f}
$$

where $B$ is a geometric constant related to the bed roughness. If we take $N=50 \mathrm{kPa}$ at $\mathrm{UpB}$ from Blankenship and others (1987), then Equations (5), (6), and the calculated values of $\tau_{\mathrm{b}}$ and $d$ at $\mathrm{UpB}$ allow us to estimate $B$. The values of $\tau_{b}$ and $d$ along the ice stream (Fig. 2) then allow us to calculate $N$ along the ice stream for constant $B$. The result is that $\beta \approx 2$, leading to the values of $N$ shown in Figure 2.

\section{Sliding and bed deformation}

The calculated water-film thicknesses (Fig. 2) are typically several millimeters, similar to the controlling obstacle size for sliding under these conditions (Weertman, 1964; see part I, equation (27), and part II, equation (4)). This allows the sliding velocity, $u_{\mathrm{s}}$, to be approximated as

$$
u_{\mathrm{s}}=K_{\mathrm{s}} \tau_{\mathrm{b}}^{2} d
$$

where $K_{\mathrm{S}} \approx 2 \times 10^{-6}\left(\mathrm{~m} \mathrm{a}^{-1}\right) \mathrm{Pa}^{-2} \mathrm{~m}^{-1}$ based on Weertman (1964) sliding theory as discussed for equation (4) in part II. Equation (7) yields a sliding velocity of about $3 \mathrm{~m} \mathrm{a}^{-1}$ at UpB. Assuming that $K_{\mathrm{s}}$ is constant along the ice stream (that is, that the roughness of the ice-bed interface does not vary along flow), the variation in sliding velocity along flow comes from variation in $\tau_{\mathrm{b}}$ and $d$, and is shown in Figure 2. Weertman sliding theory allows some latitude in calculating $K_{\mathrm{s}}$ (e.g. Weertman, 1964, 1969) because of uncertainties regarding exact conditions at the bed; however, it is difficult to construct a scenario in which $u_{\mathrm{s}}$ accounts for a significant fraction of the total ice velocity over the assumed bed.

We thus model the ice stream assuming that most of the ice velocity arises from deformation in the bed. Although ploughing and discrete shearing may account for some velocity, at Breiđamerkurjökull most of the velocity arises from pervasive deformation (Boulton and Hindmarsh, 1987). We will start by assuming that all of the deformational velocity arises from pervasive shear, and that this shear obeys the flow law (part II, equation (24))

$$
\left|\frac{\partial u}{\partial z}\right|=K_{\mathrm{b}} \frac{\left(\tau_{\mathrm{b}}-\tau^{*}\right)^{a}}{N^{b}}
$$

where $z$ and $u$ are depth and horizontal velocity in till, respectively, $K_{\mathrm{b}}, a$, and $b$ are constants, and $\tau^{*}$ is the shear strength of till.

We will follow the preferred path of Boulton and Hindmarsh (1987) in modeling Equation (8) with $\tau^{*}=0$ and $N$ independent of $z$ initially. This approach reveals the interesting features of the system more clearly and, as discussed in the sub-section on sensitivity, it can be generalized easily. Boulton and Hindmarsh (1987) measured $N$ near the ice-till interface, calculated its variation with depth in the till, and obtained an average value of $N$ to use in comparisons between sites; allowing $N$ to vary with depth produces model results that can be related directly to this fixed $N$ case, as shown below. The total velocity, $u_{0}$, arising from the deformation in a till layer $z_{1}$ thick then is

$$
u_{0}=z_{1} \overline{\frac{\partial u}{\partial z}}
$$

where the average is taken over the deforming till thickness. Because the till thickness $(6 \mathrm{~m})$ is much less than the ice thickness $(\approx 1000 \mathrm{~m}), \tau_{\mathrm{b}}$ is nearly independent of $z$ in the till, and we make the thin-till approximation that $\tau_{b}$ is independent of $z$. Then, if $N$ is independent of $z, \partial u / \partial z$ is a constant and the average in Equation (9) is unnecessary.

\section{MODEL}

Equations (1)-(9) plus the assumptions embedded in the discussion of these equations provide a complete description of the basal velocity of a cold, two-dimensional, wet-based glacier flowing on a deforming bed, provided that the ice 
and till geometries (till thickness and basal shear stress) are known. Equations $(7)-(9)$ yield the basal velocity, $u_{i}$, when combined with

$$
u_{\mathrm{i}}=u_{0}+u_{\mathrm{s}}
$$

Equations (1)-(6) show how the water system determines the effective pressure, $N$, and the water-film thickness, $d$, and thus the deformational velocity, $u_{0}$, and the sliding velocity, $u_{\mathrm{S}}$.

The system specified here is quite simple, but we believe that it incorporates most of the real behavior of an ice stream on deforming till. The grain-size distribution of a till controls the roughness of its upper surface, and thus the sliding softness, $K_{\mathrm{S}}$, as well as the details of internal shear, and thus the deformational softness, $K_{\mathrm{b}}$. The interaction of the water supply with the basal shear stress, the pressure-gradient driving water flow, and the roughness of the upper surface of the bed produces a unique average water-film thickness and effective pressure at the ice-bed interface. The sliding softness, water-film thickness, and basal shear stress then yield the sliding velocity, and the deformational softness, effective pressure, till thickness, and basal shear stress yield the deformational velocity; the sum of these two is the basal ice velocity.

Our approach is to use Equations (1)-(6) to estimate $N$ and $d$, and to obtain $u_{\mathrm{i}}$ and $\tau_{\mathrm{b}}$ from the idealized version of the ice stream described above and shown in Figures 1 and 2 . If the constants $a, b, B, K_{\mathrm{s}}$, and $K_{\mathrm{b}}$ were known independently, then they would provide a second estimate of $u_{i}$ from Equations $(7)-(10)$. Unfortunately, although we can limit the values of these constants, none is known exactly. We will limit these constants as closely as possible, and then determine which combination(s) within the limits reproduce the idealized ice stream best.

The tills beneath the Ross Sea above the Ross Sea unconformity are not strongly variable spatially (Anderson and others, 1980), and we argued above that the tills beneath Ice Stream B are likely to be similar. We thus assume that the grain-size distribution is independent of position (horizontal and vertical) in the deforming till beneath Ice Stream $B$, and that $K_{\mathrm{b}}, K_{\mathrm{s}}$, and $B$ are independent of position as well.

The constant $\beta$ can be estimated from Equation (6) using the seismically estimated effective pressure of $N=50 \pm 40 \mathrm{kPa}$ at UpB (Blankenship and others, 1987), as noted above. Assuming $N=50 \mathrm{kPa}$ gives $B \approx 2$; the effects of water-pressure variation with depth and of the $\pm 40 \mathrm{kPa}$ error are discussed below.

The calculations of sliding above and in part II show that $K_{\mathrm{S}}$ takes on small values for a rough till bed, and that sliding of Ice Stream $B$ is likely to be slow. However, uncertainties in interactions of stress fields around clasts and in other factors make it difficult to constrain $K_{\mathrm{S}}$ exactly. We find it convenient to define a new parameter, $\gamma$, to be the fraction of the total velocity at $\mathrm{UpB}, u_{\mathrm{iB}}=448 \mathrm{~m} \mathrm{a}^{-1}$, accounted for by sliding at $\mathrm{UpB}, u_{\mathrm{SB}}$, or

$$
\gamma \equiv \frac{u_{\mathrm{SB}}}{u_{\mathrm{iB}}}
$$

Each value of $\gamma$ thus is linked directly to a value of $K_{\mathrm{s}}$, and the calculations above require that $\gamma \ll 1$ (sliding velocity at $\mathrm{UpB}$ small compared to total velocity).

For $\tau^{*}=0$ and $N$ independent of $z$ in Equation (8), Boulton and Hindmarsh (1987) determined empirically that $a=1.33, \quad b=1.8$, and $K_{\mathrm{b}}=2.8 \times 10^{-5} \mathrm{~Pa}^{0.47} \mathrm{~s}^{-1}$ at Breiđamerkurjökull. They did not report uncertainties, but we estimate standard errors of $\pm 0.2-0.3$ on the determination of $a$ and $b$. We thus look for solutions with $a$ and $b$ within one to two standard errors of the Boulton and Hindmarsh (1987) values. We focus on solutions with $a=1$ because $a=1$ is mathematically simple, and because $a=1$ falls within the likely error bounds from Boulton and Hindmarsh (1987).

The till at Breiđamerkurjökull is relatively coarsegrained compared to the tills beneath the Ross Sea used as a basis for our calculations (Barrett, 1975; Anderson and others, 1980; Boulton and Hindmarsh, 1987). Addition of clasts is known to strengthen earth flows in viscous defor- mation (Rodine and Johnson, 1976; Hampton, 1979). We thus expect $K_{\mathrm{b}}$ to be larger for Ice Stream $B$ than for Breidamerkurjökull, but we do not know by how much.

Computationally, we estimate $u_{i}, \tau_{b}, d$, and $N$ along the idealized ice stream using $B$ calculated at UpB. We then assume values for $\gamma$ (and thus $K_{s}$ ), $a$, and $b$, and calculate $u_{\mathrm{s}}$ from Equation (7) and $u_{\mathrm{d}}$ from Equation (10). These results plus the assumed value of $z_{1}$ allow us to calculate $K_{\mathrm{b}}$ from Equations (8) and (9) at each point along the idealized ice stream. Each set of $(a, b, \gamma)$ yields a curve of $K_{\mathrm{b}}(x)$, but we argued above that $K_{\mathrm{b}}$ is likely to be independent of $x$. What we take as the "best fit" between model and real ice streams is that combination of $(a, b, \gamma)$ that minimizes variation in $K_{\mathrm{b}}$ along the model ice stream and that meets the criteria of $a, b$ within the error limits of Boulton and Hindmarsh (1987), $\gamma$ small, and $K_{\mathrm{b}}$ larger than for Breiđamerkurjökull.

Results are shown in Figure 3, where we plot the maximum relative variation in $K_{\mathrm{b}}$ from $x=100 \mathrm{~km}$ to

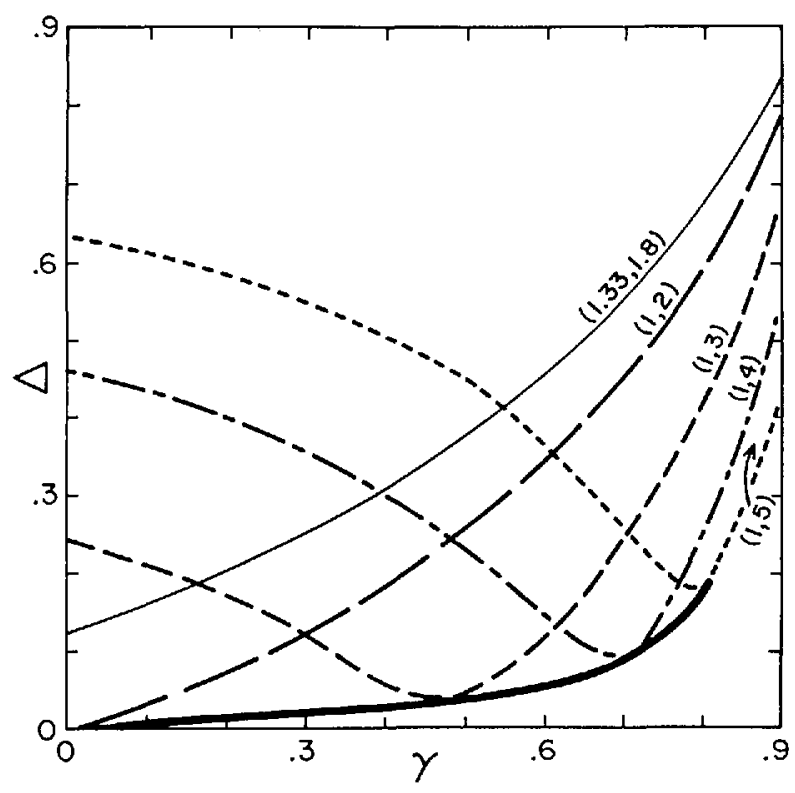

Fig. 3. Relative variation in modeled till-softness parameter, $K_{b}$, as a function of $\gamma$, the fraction of the ice velocity at $U p B$ arising from sliding, for different parts of exponents $(a, b)$ in Equation (8). The variation is given as $\left.\Delta=\left(K_{b \max }{ }^{\prime}-K_{b \min }{ }^{\prime}\right) / K_{b \max }{ }^{\prime}+K_{b \min }{ }^{\prime}\right)$, where $K_{b \max }{ }^{\prime}$ and $K_{b \min }$ are the maximum and minimum values of $K_{b}$, respectively, from $x=100 \mathrm{~km}\left(U_{p B}\right)$ to $x=300 \mathrm{~km}$ for given $a, b$, and $\gamma$. Curves for $(a, b)=(1.33,1.8),(1,2)$, $(1,3),(1,4)$, and $(1,5)$ are indicated; the heavy solid line connects the minima in $\Delta$ for $a=1, b=2,3,4,5$.

$x=300 \mathrm{~km}$ as a function of $\gamma$ for different pairs of $a$ and $b$. For instructional purposes, we deliberately have allowed $a, b$, and $\gamma$ to vary past likely limits; only the $(a, b)$ pairs $(1.33,1.8)$ and $(1,2)$ in Figure 3 fall within the likely error limits of Boulton and Hindmarsh (1987), and only small $\gamma$ are acceptable from Weertman-sliding calculations.

It is evident that the Boulton and Hindmarsh (1987) relation, $a=1.33, b=1.8$, gives a moderately good fit at small $\gamma$, with an increase in $K_{b}$ of about $12 \%$ down-stream. The absolute value of $K_{\mathrm{b}}\left(1.4 \times 10^{-3} \mathrm{~Pa}^{0.47} \mathrm{~s}^{-1}\right)$ is higher than for Breiđamerkurjökull $\left(2.8 \times 10^{-5} \mathrm{~Pa}^{0.47} \mathrm{~s}^{-1}\right)$, as expected.

A better fit is obtained for $a=1, b=2$, and small $\gamma$. Variation in $K_{\mathrm{b}}$ from $x=100 \mathrm{~km}$ to $x=300 \mathrm{~km}$ (plotted in Figure 3 ) is minimized for $\gamma \approx 0$ and amounts to only about $0.3 \%$; variation from $x=25 \mathrm{~km}$ to $x=300 \mathrm{~km}$ is minimized for $y \approx 0.05$ and amounts to about $1 \%$ (see Fig. 4). For $a=1, b=3,4,5$, the value of $\gamma$ that minimizes variation in $K_{\mathrm{b}}$ increases with increasing $b$ (Fig. 3). The minimum variation in $K_{\mathrm{b}}$ also increases with $b$ and the pattern of variation of $K_{\mathrm{b}}$ along the flow line becomes complicated (Fig. 4). Thus, models with $b \geqslant 3$ give a poor fit. In addition, $b \geqslant 3$ falls outside of likely error 

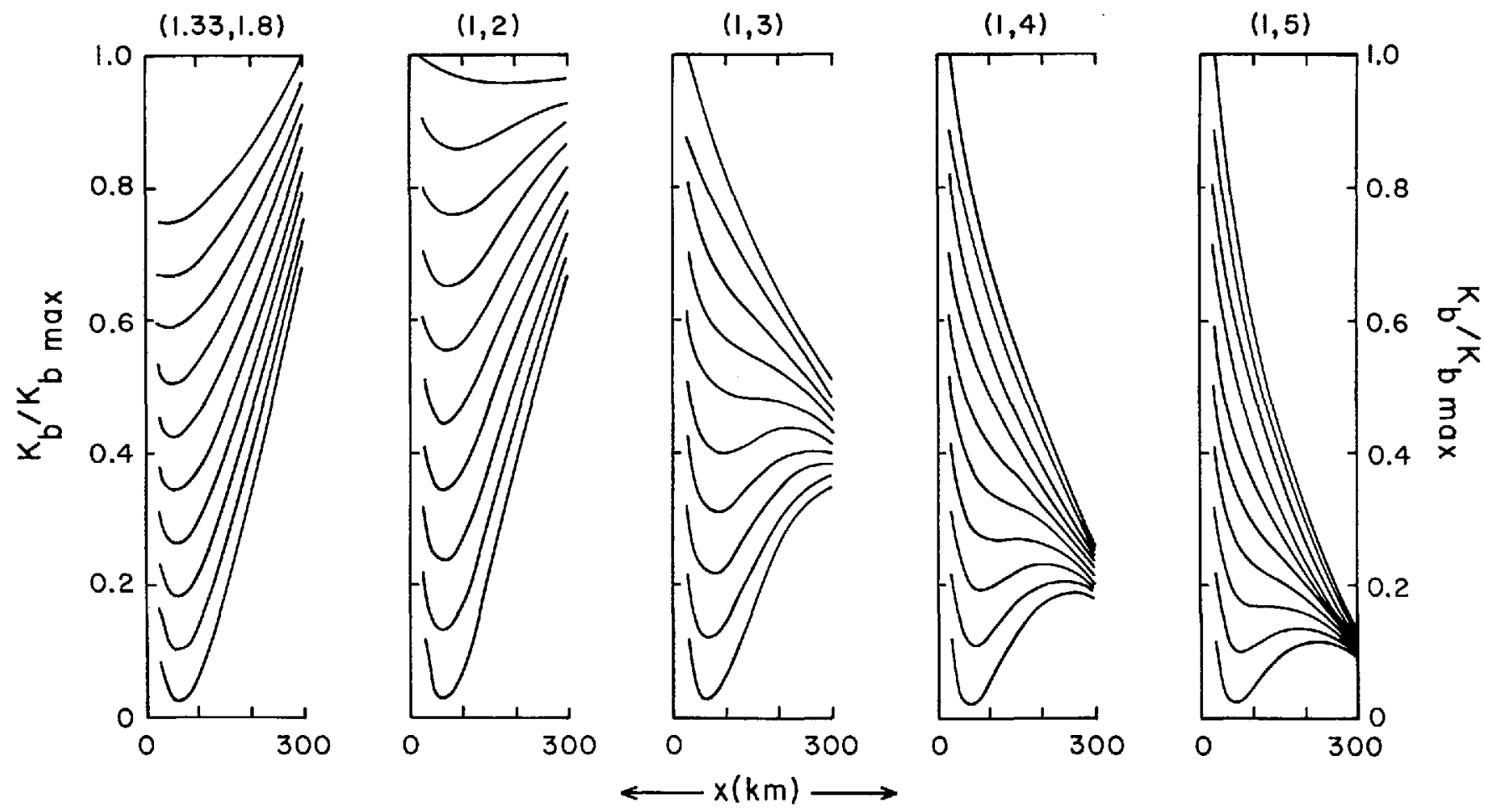

Fig. 4. Variation in modeled till-softness parameter, $K_{b}$, as a function of position, $x$, for different pairs of exponents $(a, b)$ in Equation (8) and for different values of $\gamma$. The softness parameter, $K_{b}$, is plotted normalized by $K_{b \max }$, its maximum value for given $(a, b)$ over all $\gamma$ and $x$ from 25 to $300 \mathrm{~km}$. The values of $(a, b)$ are indicated above each section of the figure. From top to bottom in each section, the curves are $\gamma=0,0.1,0.2, \ldots .0 .9$. The most nearly horizontal curve in each section correponds to the best-fit value $\gamma$ for $(a, b)$ in that section.

bounds from Boulton and Hindmarsh (1987) and large $\gamma$ is unlikely based on calculations presented above, so these models are discarded.

We could conduct a formal inversion for those values of $a, b$, and $\gamma$ that minimize variations in $K_{\mathrm{h}}$ along the model ice stream. However, it is clear from the results presented above that $a \approx 1, b \approx 2$, and $\gamma \approx 0-0.1$ provide an excellent fit, with variation in $K_{\mathrm{b}}$ of $\leqslant 1 \%$ along the ice stream. Any improvement in this fit that might result from using decimal powers (e.g. $b=2.01$ ) would not be statistically significant and would complicate the resulting flow law for till. We thus feel justified in using our simple forward approach to this inverse problem, and in taking $a \approx 1, b \approx$ 2 , and $\gamma \approx 0-0.1$ as our best solution.

\section{Sensitivity study and discussion of assumptions}

The analysis above clearly is based on a number of assumptions. Most of these can be tested by surface geophysical and bore-hole studies of the ice-stream bed, and we expect such tests in the future. However, a complete data set is unlikely to be assembled for years, if ever. In the interim, the best we can do is to assess likely errors in assumed or inferred quantities, and to test how sensitive our results are to those errors.

The main inference, that bed deformation contributes a significant fraction of the total velocity of Ice Stream B (Alley and others, 1987b), is drawn from solid geophysical evidence (Blankenship and others, 1987, 1989; Rooney and others, 1987b, 1988). The alternative of a rigid or nearly rigid bed would require that the data or the inferences drawn from the data are in error. In addition, a rigid bed would require some combination of a smoother bed, thicker water layer, or error in the sliding law at UpB sufficient to allow the sliding velocity to be more than two orders of magnitude faster than calculated above, and to allow a further down-stream increase in sliding velocity not accounted for by modern sliding theory so that the error in sliding velocity calculated above approaches three orders of magnitude at the down-stream end. Although not impossible, we believe such errors to be unlikely, and we do not consider this possibility $(\gamma=1)$ further.

However, it is possible that errors in sliding calculations are sufficiently large to allow significant sliding (and ploughing?) over a pervasively deforming bed (intermediate $\gamma$ ). Such a situation would not invalidate the inferences based on seismic data at $\mathrm{UpB}$. It would require some ad hoc modifications in our assumed distribution of till roughness or softness along the ice stream. We now do not obtain good solutions for intermediate $\gamma$ (see Fig. 4). Suppose that $a=1, b=2, \gamma=0.3$ (which requires that sliding has been underestimated by a factor of 45 at UpB). Then an exact $f$ it with constant $K_{\mathrm{s}}$ would require $K_{\mathrm{b}}$ to vary as shown in Figure 4 in the $(1,2)$ section for the $\gamma=0.3$ curve (fourth from the top); that is, a slight decrease followed by a $32 \%$ increase in the down-stream direction.

The calculation of effective pressure, $N$, used the geometric factor $\beta$ from Equation (6), which we calculated using the seismically estimated effective pressure of $50 \pm 40$ $\mathrm{kPa}$ at UpB (Blankenship and others, 1987). The error limits on $N$ produce a corresponding error in $\beta(\beta=2.1 \pm 1.6)$. However, an error in $B$ means only that all estimates of $N$ along the flow line are in error by a constant multiplicative factor of between 0.2 and 1.8 , and thus that our estimate of $K_{\mathrm{b}}$ for any chosen $(a, b, \gamma)$ will be in error by that multiplicative factor raised to the power $b$. The only restriction we could place on $K_{\mathrm{b}}$ was that it exceed the value calculated for Breiđamerkurjökull (Boulton and Hindmarsh, 1987), which it does for the full range of $B=$ $2.1 \pm$ 1.6. Thus, errors in $\beta$ have no significant effect on our result.

The assumption of constant deforming-layer thickness, $z_{1}$, does affect the result significantly. The thickness at $\mathrm{UpB}$ is relatively well determined seismically at about $6 \mathrm{~m}$ (Rooney and others, 1987b), but there is more uncertainty in our knowledge of $z$ at the down-stream end (Blankenship and others, 1989). Suppose we let $z_{1}=6 \pm$ $3 \mathrm{~m}$ at the down-stream end, $z_{1}=6 \mathrm{~m}$ at UpB, and we assume that $z_{1}$ varies linearly along the ice stream. If we further assume that $a=1$, then we can assess the impact of errors in $z_{1}$ on $b$. The best fit for a $9 \mathrm{~m}$ thick deforming layer at the down-stream end with $a=1$ is $b \approx 1$, $\gamma \approx 0$, whereas for $3 \mathrm{~m}$ thick till there it is $b \approx 3, \gamma \approx 0$.

This result is relatively easy to understand. The shear stress decreases down-stream, but the sliding velocity remains low and is calculated to decrease down-stream from 
UpB. At the same time, the total velocity increases downstream. With constant $K_{\mathrm{b}}$, the down-stream increase in velocity must arise from thicker or softer till down-stream. The effective pressure, $N$, decreases down-stream and causes the till to soften down-stream. If the till thins down-stream, then the inverse dependence of softness on $N$ must be strong (large $b$ ), whereas if the till thickens down-stream, this dependence can be weak (small b).

Another important assumption is that of $N$ independent of $z$. It is not difficult to show that allowing $N$ to increase with depth in till will increase the value of $b$ in the bestfit result by an additive factor of zero to one, as compared to the case of depth-independent $N$.

To see this, return to the coordinate system of part II, with $z=0$ at the ice-till interface, positive downward. Set $\tau^{*}=0$ in Equation (8), take $\tau_{\mathrm{b}}$ and $N$ to be independent of $z_{1}$, and let $u=u_{0}$ at $z=0$ and $u=0$ at $z=z_{1}$. Then, integrating Equation (8) through the till thickness and solving for $K_{\mathrm{b}}$ yields

$$
K_{\mathrm{b}}=\frac{u_{0} N_{0}^{b}}{\tau_{\mathrm{b}}^{a} z_{1}}
$$

The variation of effective pressure with depth can be written (part II, equation (17))

$$
N=N_{0}+\Delta \rho g z
$$

where $N_{0}$ is the effective pressure at $z=0$ (the ice-bed interface), $\Delta \rho$ is the difference between the bulk density and the pore-fluid density, and $g$ is the gravitational acceleration. (If downward water flow to an aquifer were to occur, then $N$ would increase with depth more rapidly than given by Equation (13). This could be modeled by defining $\Delta \rho \equiv \rho_{\mathrm{b}}-\rho_{\mathrm{w}}(1-\partial H / \partial z)$ where $\rho_{\mathrm{b}}$ and $\rho_{\mathrm{w}}$ are the bulk and water densities, respectively, and $H$ is the hydraulic head. The assumption of no vertical water flow is equivalent to assuming $H$ independent of $z$.) Substituting Equation (13) into Equation (8) with $\tau^{*}=0$, integrating through the thickness, and solving for the sof tness coefficient yields

$$
K_{\mathrm{b}}^{\prime}=\frac{u_{0}\left(b^{\prime}-1\right) \Delta \rho g N_{0}^{b^{\prime}-1}}{\tau_{\mathrm{b}}^{a}\left[1-\left[\frac{\Delta \rho g z_{1}}{N_{0}}+1\right)^{1-b^{\prime}}\right]}
$$

where primed quantities refer to the case of depth-varying $N$. (Equation (14) is valid only for $b \neq 1$; a similar expression with logarithmic terms arises for $b=1$. We generally expect $b>1$, and so do not display this.)

Two limits bear consideration in Equation (14). If $\Delta \rho g z_{1} \ll N_{0}$ (variation in effective pressure across layer small compared to effective pressure at the top), then Equation (14) reduces to Equation (12) and $b^{\prime}=b$. If $\Delta \rho g z_{1} \gg N_{0}$ (variation in effective pressure across layer large compared to effective pressure at top) then Equation (14) reduces to

$$
K_{\mathrm{b}}^{\prime} \approx \frac{u_{0} \Delta \rho g\left(b^{\prime}-1\right) N_{\mathrm{0}}^{b^{\prime}-1}}{\tau_{\mathrm{b}}^{a}}=\frac{\Delta \rho g\left(b^{\prime}-1\right) z_{1} N_{0}^{b-1}}{N_{\mathrm{0}}^{b}} K_{\mathrm{b}} .
$$

Because $\Delta \rho, g, b^{\prime}$, and $z_{1}$ are constants in any experiment, Equation (15) shows that the best fit is obtained for $b^{\prime}=$ $b+1$. Thus, if $(a, b, \gamma) \approx(1,2,0-0.1)$ for depth-independent effective pressure, we expect the same result if effective pressure varies with depth but $\Delta \rho g z_{1} \ll N_{0}$, and we expect $\left(1,3,0-0.1\right.$ if $\Delta \rho g z_{1} \gg N_{0}$; the complete range of possibilities is spanned by $(1,2-3,0-0.1)$.

Near the UpB camp, seismic measurements give $N=50 \pm 40 \mathrm{kPa}$ averaged over a local till thickness of $8 \mathrm{~m}$ (Blankenship and others, 1987). (The average till thickness near UpB is $6 \mathrm{~m}$, but there are local variations (Rooney and others, 1987b).) Ice Stream $B$ is unlikely to experience significant vertical drainage into subglacial aquifers (Lingle and Brown, 1987; also see above and part I), meaning that the depth variation of pressure is limited by the lithostatic $(\Delta \rho=0)$ and hydrostatic $\left(\Delta \rho \approx 10^{3} \mathrm{~kg} \mathrm{~m}^{-3}\right)$ cases (part II, equations (17) and (18)). In the hydrostatic case, $N$ varies vertically by about $10 \mathrm{kPa} / \mathrm{m}$. If we assume that $N=50 \pm$ $40 \mathrm{kPa}$ applies to the center of the till at $z=4 \mathrm{~m}$ at $\mathrm{UpB}$, and that the hydrostatic case applies, then $N_{0}=10 \pm$ $40 \mathrm{kPa}$. Physically, $N_{0} \leqslant 0$ cannot occur over large areas because it would imply floating ice and zero basal shear stress, whereas a non-zero basal shear stress exists. We thus take $0<N_{0} \leqslant 50 \mathrm{kPa}$ in the hydrostatic case.

For till averaging $z_{1}=6 \mathrm{~m}$ thick with a hydrostatic pressure gradient, $\Delta \rho g z_{1} \approx 60 \mathrm{kPa}$. If $N_{0} \approx 0$, then $\Delta \rho g z_{1}$ $\gg N_{0}$ and we expect $b \approx 3$; however, if $N_{0} \approx 50 \mathrm{kPa}$, then $\Delta \rho g z_{1} \approx N_{0}$ and we expect $b$ between 2 and 3 . Computer simulations give $b=3.0$ for $N_{0} \approx 0$ and $b=2.7$ for $N_{0}=$ $50 \mathrm{kPa}$, as expected.

The assumptions $\tau^{*}=0$ (no yield strength) proves to affect the results mainly through its control on the deforming thickness, provided that cohesion is small. If $N$ is independent of depth, then

$$
\begin{aligned}
& \tau_{\mathrm{b}}-\tau^{*} \approx \tau_{\mathrm{b}}-N \tan \phi \\
& \tau_{\mathrm{b}}-\tau^{*} \approx \tau_{\mathrm{b}}\left(1-\frac{\beta}{f} \tan \phi\right)
\end{aligned}
$$

from equation (22) in part II with cohesion set to zero, and from Equation (6). The fraction of the bed flooded, $f$, varies only slowly along flow, and $B$ and $\tan \phi$ are constants. Thus, $\tau^{*}$ is approximately a constant multiplied by $\tau_{\mathrm{b}}$, and $\tau-\tau^{*}$ is a different constant multiplied by $\tau_{\mathrm{b}}$. The resulting $(a, b, \gamma)$ are essentially the same as the $\tau^{*}=0$ case, but with the magnitude of $K_{\mathrm{b}}$ changed slightly, giving $(a, b, \gamma) \approx(1,2,0-0.1)$ for cohesionless till with non-zero internal friction and depth-independent effective pressure.

If we allow cohesion and increase of effective pressure with depth, then Equation (16) becomes

$$
\tau_{\mathrm{b}}-\tau^{*}=\tau_{\mathrm{b}}\left(1-\frac{B}{f} \tan \phi\right)-\left(\Delta \rho g z_{1} \tan \phi+C\right) .
$$

The effect of choosing some combination of $\Delta \rho, \tan \phi$, and $C$ such that $\tau^{*}$ is as large as possible without reducing the deforming thickness below $6 \mathrm{~m}$ anywhere along the flow line (i.e. without making $\tau^{*}>T_{\mathrm{b}}$ at $z_{1}=6 \mathrm{~m}$ ) is to increase $b$ to about 3 for $a=1$, but with $y=0-0.1$ still. Smaller $\tau^{*}$ reduces $b$ back toward 2 , and larger $\tau^{*}$ reduces the deforming thickness down-stream and increases $b$ to about 4 for a $3 \mathrm{~m}$ till at the down-stream end.

We have assumed that all of the ice velocity arises from sliding and pervasive till deformation. Clearly, if some additional deformational mechanisms are active, this assumption could introduce errors. Possible candidates include ploughing and shearing on discrete planes.

Ploughing was defined for motion over a rigid bed (Brown and others, 1987), but one can conceive of accelerated motion of some clasts through a bed undergoing slow pervasive deformation. Unless there are quite steep vertical gradients in effective viscosity, however, our calculations (see "ploughing" in part II) suggest that such localized velocity is unlikely to be large. Large ploughing velocities were not reported at Breiđamerkurjökull (Boulton, 1979) or Blue Glacier (Engelhardt and others, 1978) (see "ploughing", part II). It thus seems quite reasonable to partition the velocity near the ice-till interface to sliding and pervasive deformation only.

Discrete shear at the base of the till is more problematic. Boulton and Hindmarsh (1987) found that at Breiđamerkurjökull, where a pervasively deforming till overlies a lodged till that differs from it only in ways related directly to the deformation, a significant fraction $(10-30 \%)$ of the total deformational velocity arises from shearing on discrete surfaces in the deeper layer (see section on "velocity-depth profiles", part II). We could introduce an explicit relation for velocities from discrete shearing. The total velocity would increase with shear stress and with the inverse of effective pressure, the same as for pervasive deformation, but the form of the relation is poorly constrained. Implicitly treating discrete shearing as part of pervasive deformation may be as accurate as any other approach, especially considering that discrete shearing seems 
unlikely to be the dominant contributor to basal velocity. We thus feel justified in not treating discrete shearing explicitly; below we discuss whether such shearing is likely beneath Ice Stream B.

To recapitulate, we assume that the basal system of Ice Stream B obeys Equations $(1)-(10)$, and that the grain-size distribution controls the geometric factors $K_{\mathrm{S}}, K_{\mathrm{b}}$, and $B$, and does not vary along flow. The longitudinal profile of the ice stream, as idealized in Figure 1, then requires that $b \approx 2, \gamma \approx 0-0.1$ for $a=1$ in Equation (8), if $\tau^{*}=0$ and $N$ is independent of depth in the till and if the deforming till thickness is constant along the ice stream. Allowing $N$ to vary with depth in the till increases $b$ to between 2 and 3. Allowing $\tau^{*}$ to be significant but setting the cohesion to zero has little effect on $b$; increasing the cohesion acts with depth-varying $N$ to increase $b$ toward 3 . If the deforming till thickness varies, owing to the effect of $\tau^{*}$ or to a lithologic change, then $b$ also varies; a $3 \mathrm{~m}$ thickening from UpB to the down-stream end reduces $b$ by about 1 , and $a$ $3 \mathrm{~m}$ thinning from $\mathrm{UpB}$ to the down-stream end increases $b$ by about 1

\section{VERTICAL PROFILE}

The field programs dedicated to studying the subglacial till of Ice Stream B have concentrated on lateral variations, and only limited data are available bearing on the vertical profile of deformation. Future drilling programs should provide useful data, but our hypotheses on the vertical profile now are poorly constrained.

Three lines of evidence are available to us: analogy to other sites, physical reasoning from flow laws (constrained by the longitudinal profile), and available seismic data. All three provide some information. The best data are available from $U p B$, and future drilling is likely there, so we concentrate on that site.

Above, we used a combination of all three lines of evidence to show that rapid sliding between ice and till, with or without ploughing, is unlikely beneath the $300 \mathrm{~km}$ of Ice Stream B treated in our model. (It remains possible that sliding occurs beneath the ice plain down-stream of the area treated here (Alley and others, 1987b).) We thus expect velocity localized at the ice-till interface to account for $<10 \%(<50 \mathrm{~m} / \mathrm{a})$ of the ice velocity near $\mathrm{UpB}$, and probably only about $0-10 \mathrm{~m} / \mathrm{a}$.

As discussed in part II, Boulton and Hindmarsh (1987) observed that $\leqslant 10 \%$ of the basal velocity was localized at the ice-till interface, that pervasive deformation in a till layer accounted for most of the basal velocity, and that discrete shearing occurred in an underlying till not undergoing pervasive deformation; we inferred that such discrete shearing accounted for $10-30 \%$ of the total basal velocity there. We thus must consider the possibility of shearing or localized deformation beneath a pervasively deforming layer.

At $\mathrm{UpB}$, the layer we infer to be a deforming till is underlain by hundreds of meters of sediments with low seismic velocities; based on seismic character and analogy to known sequences in the region, these probably are poorly indurated, Neogene glaciomarine sediments (Rooney and others, in press). They thus fall somewhere between welllithified bedrock, which would be unlikely to shear within its bulk, and unlithified sediments, which have been observed to shear locally beneath pervasively deforming till. We lack sufficient knowledge to favor one extreme or the other (zero shearing or $10-30 \%$ of velocity by shearing beneath the pervasively deforming layer) at UpB, but a reasonable guess is that the actual behavior falls between these extremes.

Detailed analysis of the seismic results from $U p B$ provides further insight to this problem. The base of the deforming till, as identified by Blankenship and others (1986, 1987) and mapped by Rooney and others (1987b, 1988), occurs about $6 \mathrm{~m}$ below the ice bottom. Below that, there exists a seismically quiet zone of approximately equal thickness, followed by the thick sequence of layered, gently dipping sediments (Rooney, unpublished; also see figs 4-8 in Rooney and others, 1987b). These deeper sediments definitely are truncated by an angular unconformity at the top. It is difficult to resolve, but this truncation may be at the base of the seismically quiet zone rather than at the base of the deforming till.

We can suggest a number of possible explanations for these observations: (1) the quiet zone is an artifact of data processing; (2) the quiet zone is a continuation of the deforming till and the reflector mapped as the till base actually is an intra-till reflector; (3) the quiet zone is a lodged till, which currently may be experiencing erosion, no change, or deposition with or without discrete shearing; and (4) the quiet zone is a region of slow, discrete shear within the sub-till sediments (Rooney, unpublished). We consider (1) (data-processing artifact) to be unlikely, because the data processing was conducted carefully and complex, poorly characterized analysis techniques were not used. Possibility (2) (intra-till reflector) also seems unlikely, because the large amplitude of the first sub-ice-bottom reflector identified by Blankenship and others $(1986,1987)$ indicates that it is a fundamental discontinuity, rather than a subtle change within a relatively homogeneous mass.

Possibilities (3) (lodged till) and (4) (discrete shearing in sub-till sediments) both deserve further consideration. We certainly can construct a plausible history for Ice Stream B that would allow it to be underlain by an older, lodged till resting unconformably on deeper sediments, and so this should be a working hypothesis. The major objection to this idea is that $\mathrm{UpB}$ is an area of extending, channelized ice flow, and such areas typically are characterized by basal erosion to bedrock rather than deposition (Sugden and John, 1976, chapter 9); an hypothesis that requires deposition or incomplete erosion in such an area may not be parsimonious.

Possibility (4) (discrete shearing in sub-till sediments) also should be a working hypothesis. In this scenario, slow shear has partially homogenized the upper few meters and caused the seismically quiet zone beneath the till by disrupting the dipping beds there. Erosion would then consist of incorporation of sediments into the pervasively deforming till at its base, and of concurrent development of new shear planes deeper in the sub-till sediments. In terms of velocity-depth profiles, possibility (4) seems to require shear beneath the pervasively deforming till to cause the seismically quiet zone, and possibility (3) allows such shear. We tend to favor (4) as being more parsimonious, but both are possible.

Within the pervasively deforming till, the velocitydepth profile also is open to considerable uncertainty. The study of Boulton and Hindmarsh (1987), our re-analysis of their data (part II), and our analysis of the long profile of Ice Stream B, above, suggest that a flow law in the form of Equation (8) with $a=1, b \approx 2-3$ provides a reasonable approximation to subglacial till deformation. The velocitydepth profile from pervasive deformation then should be given by equation (28) and table $I$ in part II, if the constants $z_{0}, z_{1}$, and $z_{2}$ are specified.

The deforming thickness, $z_{1}$, is estimated seismically as about $6 \mathrm{~m}$ (Rooney and others, 1987b). The value of $z_{0}$ is the depth in the till at which the effective pressure, $N$, is double the value at the ice-till interface, $N_{0}$. The effective pressure averaged over $8 \mathrm{~m}$ of till at one spot near $U p B$ is known to be $N=50 \pm 40 \mathrm{kPa}$ (Blankenship and others, 1987). As discussed above, the depth variation of effective pressure beneath the ice stream is limited by the lithostatic case (effective pressure independent of depth) and the hydrostatic case (effective pressure increases downward at about $10 \mathrm{kPa} / \mathrm{m})$. In the lithostatic case, $z_{0} \rightarrow \infty$. In the hydrostatic case, letting $N=50 \mathrm{kPa}$ at $z=4 \mathrm{~m}$ gives $N_{0}=$ $10 \pm 40 \mathrm{kPa}$. Physically, $N_{0}>0$, and as discussed in part $\mathrm{I}$, $N_{0}$ is unlikely to be much less than $10 \mathrm{kPa}$. Then, for $N_{0}=$ $10 \mathrm{kPa}$, we obtain $z_{0}=1 \mathrm{~m}$ as the best estimate; however, $N_{0}=0$ gives $z_{0}=0$ and $N_{0}=50 \mathrm{kPa}$ gives $z_{0}=5 \mathrm{~m}$.

Direct measurement of effective pressure (or of water pressure and column density) versus depth in the till will be required to resolve this problem. However, seismic studies provide some interesting clues. In some places near UpB, shear-wave studies reveal intra-till reflectors where no $P$-wave reflectors are observed (Rooney, unpublished). The shear-wave reflections are low-frequency, suggesting that they arise from a zone of finite thickness rather than from a discrete interface (Rooney, unpublished). In unconsolidated sediments, P-wave velocities and reflections are sensitive primarily to till density, whereas $S$-waves are sensitive 
primarily to effective pressure (Blankenship and others, 1987). A change in effective pressure across a zone thus might generate low-frequency $\mathrm{S}$-wave reflections without $P$-wave reflections. The pore-water pressure should become hydrostatic at depth, as deformation slows and stops. Lithostatic or intermediate pressures changing downward to hydrostatic pressures thus might generate the observations. This analysis is at the limit of seismic resolution, and developing a quantitative model incorporating these qualitative considerations presents some difficulties (see Rooney, unpublished), so it should be considered tentative. However, it is worthy of further testing.

The depth at which the yield strength of the deforming till equals the basal shear stress, $z_{2}$, depends on the internal friction, $\tan \phi$, and cohesion, $C$, of the till, and on $N_{0}$ (equation (20), part II). For lithostatic pressures, $z_{2} \rightarrow \infty$ because the till strength does not increase with depth. On the other hand, letting $C=4 \mathrm{kPa}$ (Boulton and Hindmarsh, 1987), $\tan \phi=0.2$ (Alley and others, 1987b), and $N_{0}=10 \mathrm{kPa}$ and assuming hydrostatic effective pressures, gives $z_{2} \approx 6 \mathrm{~m}$.

If our inference of $6 \mathrm{~m}$ of deforming till is correct, then part II shows that $z_{2}>6 \mathrm{~m}$. This is because the strain-rate must exceed some minimum value (estimated at $\approx 5 \mathrm{a}^{-1}$ in part II) to maintain till in a dilated state and allow pervasive deformation.

We thus consider it likely for UpB that $z_{1} \approx 6 \mathrm{~m}, 6 \mathrm{~m}$ $<z_{2}<\infty$, and $0<z_{0}<\infty$, with the probability that $z_{0} \geqslant$ $1 \mathrm{~m}$; in addition, the combination of $z_{0}, z_{1}, z_{2}$, and $b$ should yield a strain-rate in excess of about $5 \mathrm{a}^{-1}$ as $z$ increases to $z_{1}$, and both $z_{0}$ and $z_{2}$ may vary with depth in the till. Working from this, we can construct limiting cases for velocity-depth profiles, and then select those possibilities that best fit our knowledge.

To do so, we again construct the dimensionless variables $\chi=z_{0} / z_{1}, \Psi=z / z_{1}$, and $\omega=z_{1} / z_{2}$. In the limit of $z_{0} \rightarrow \infty$ (lithostatic pressure), $\chi=\infty$ and velocity decreases linearly with increasing depth (curve 1, Fig. 5). In the limit of $z_{0} \rightarrow 0, \chi \rightarrow 0$ and the velocity drops to zero at the ice-till interface. With $b=3, \chi=1 / 6$, and $\omega=1$, we obtain curve 2 shown in Figure 5 , but the strain-rate falls below the minimum to maintain dilation at $\Psi \approx 0.5$ $(z \approx 3 \mathrm{~m})$, if that minimum is the same at UpB as at

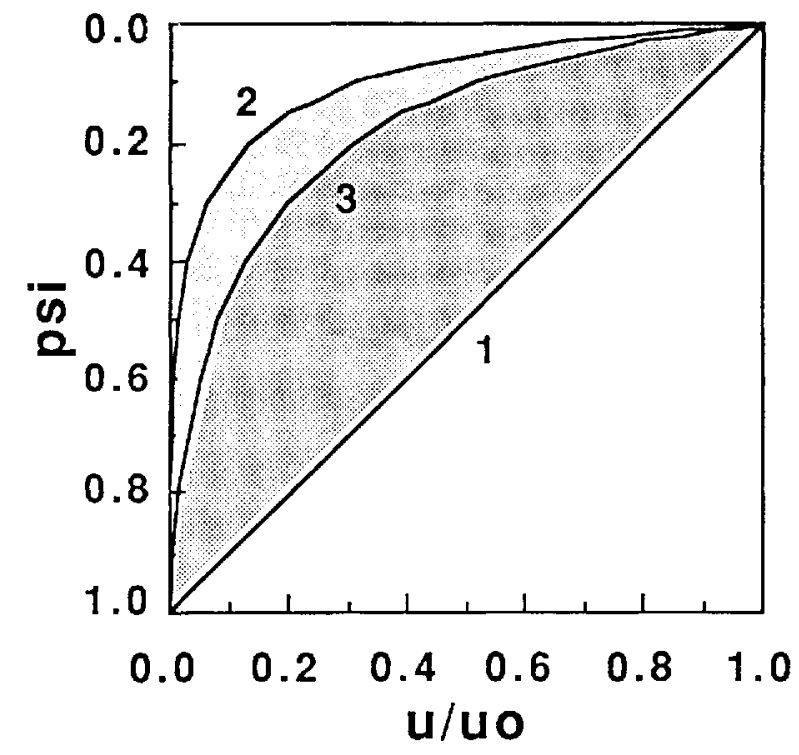

Fig. 5. Hypothesized velocity-depth profiles beneath UpB. Till velocity $(u)$ normalized by velocity at the ice-till interface $\left(u_{0}\right)$ is plotted against relative depth $\Psi\left(=p s i=z / z_{1}\right.$, where $z_{1}=6 \mathrm{~m}$ is the thickness of pervasively deforming till and $z$ is the depth). Points must plot on or above curve $1 \quad(x=\infty)$ in the thin-till approximation for widespread, pervasively deforming till in which viscosity does not decrease downward. We believe that curve $2(b=3, x=1 / 6, \omega=1)$ places an upper limit on points on the graph, and that curve $3(b=2$, $\mathrm{x}=1 / 6, \omega=0.7$ ) may be a more restrictive upper limit. We thus expect the velocity-depth profile in pervasively deforming till at $U p B$ to plot between curves 1 and 2 , and probably between curves $I$ and 3 , inclusive.
Breiđamerkurjökull. We consider that this curve and curve 1 limit the likely velocity-depth profiles in the pervasively deforming till at UpB. To maintain a strain-rate of $5 \mathrm{a}^{-1}$ at $z<6 \mathrm{~m}$ with $b=3$ and $x=1 / 6$, it is necessary to reduce $\omega$ essentially to zero (i.e. reduce the yield strength essentially to zero). By reducing $b$ to $2, x=1 / 6$ and $\omega=$ 0.7 gives curve 3 in Figure 5 . The minimum strain-rate criterion makes curves between 2 and 3 unlikely, so we expect the true behavior to fall between 1 and 3 . Notice that any discrete shearing deeper or any sliding at the ice-till interface must be added to these curves to obtain the true velocity-depth profile.

\section{HYPOTHESES}

Our analyses leave many unanswered questions, but suggest the following hypotheses for Ice Stream B, which can be tested experimentally:

The effective pressure at the ice-till interface decreases slowly down-stream.

The strain-rate in pervasively deforming till is approximated by $\left(\tau-\tau^{*}\right) / N^{b}$, where $b \approx 2-3$.

The velocity-depth profile in the $\approx 6 \mathrm{~m}$ thick pervasively deforming till falls between curves 1 and 2 in Figure 5, and probably between curves 1 and 3.

Sliding between ice and till accounts for $\leqslant 10 \%$ of the velocity along the ice stream, and probably for $\leqslant 10 \mathrm{~m} / \mathrm{a}$.

Discrete shearing occurs beneath the pervasively deforming till, accounting for perhaps $0-10 \%$ of the ice velocity, although this could increase to perhaps $10-30 \%$ of the ice velocity if the seismically quiet zone beneath the pervasively deforming till is an unconsolidated, lodged till rather than semi-lithified sediments.

The gradient in effective pressure with depth is between hydrostatic and lithostatic, inclusive, and changes within the till in at least some places.

Bore-hole measurements clearly are required to test these hypotheses. Important parameters to measure include velocity versus depth from the basal ice downward into rigid sediments, and effective pressure versus depth from the ice-till interface downward into rigid sediments. The grain-size distribution of the till also is important (including clasts up to at least centimeters in diameter), as is the nature of the seismically quiet zone (till or glaciomarine sediment). It would be useful to measure the cohesion and internal friction of the till but, considering the errors in relating laboratory to in-situ conditions, it may prove easier to measure other parameters and infer these till properties.

\section{POSTSCRIPT}

In this set of three papers, we have attempted to identify and quantify the linkages between the basal water system and various modes of basal motion of glaciers and ice sheets. We have concentrated on Ice Stream B, because of its importance to the stability of the West Antarctic ice sheet and because of the extensive data sets available from there. However, the analyses in parts I and II are largely independent of Ice Stream B, and may prove to be glaciologically useful regardless of the fate of the deforming-bed hypothesis for Ice Stream B. We have not concentrated on glacier beds with sources of channelized water, although this is an interesting and important topic; Shoemaker (1986) has advanced work in this area.

The details of glacier motion on a deforming bed clearly remain elusive. Only one in-depth study has been published to date (that of G.S. Boulton and co-workers on Breiđamerkurjökull). Bore-hole observations undoubtedly will be necessary to solve the problems of till deformation beneath thick ice; such studies have already yielded 
important information (e.g. Engelhardt and others, 1978; Fahnestock and Humphrey, 1988; Meier, 1989), and further work is planned. The technical difficulties of collecting a complete data set through a bore-hole should not be underestimated, however, and may never be solved fully. Remote-sensing and model studies thus will remain important, yielding results in their own right as well as serving to site and to interpolate between bore holes.

Is it clear from our work and that of numerous predecessors that fast glacial motion generally requires an inefficient basal water system. In addition, fast glacial motion requires that the glacier bed be either smooth (sliding) or soft (bed deformation); soft beds seem to promote inefficient drainage systems. Limited observations plus theoretical considerations show that smooth beds tend to be rigid and soft beds tend to be rough, although intermediates probably exist.

Sliding of a glacier over a rigid bed remains an active research area despite over 30 years of modern study. The general basal motion problem, including sliding, ploughing, pervasive deformation, and discrete shearing, is far more difficult and has been the focus of modern glaciological research for only about a decade. This general problem must be solved if we are to understand the stability of modern and ancient ice sheets and the origin of glacial deposits. We hope to have contributed to the solution of this problem, and we encourage further field, laboratory, and theoretical studies.

\section{ACKNOWLEDGMENTS}

We are indebted to J.S. Walder for numerous suggestions and criticisms, not all of which are answered satisfactorily here. We also thank T.J. Hughes for helpful comments on the manuscript, A.N. Mares for manuscript preparation, P.B. Dombrowski and S.H. Smith for figure drafting, and C.R. Alley for computerized figure drafting. This work was supported by the U.S. National Science Foundation under grants DPP84-12404, DPP87-16016, and DPP86-14011. This is contribution number 499 of the Geophysical and Polar Research Center, University of Wisconsin-Madison.

\section{REFERENCES}

Alley, R.B. 1989a. Water-pressure coupling of sliding and bed deformation: I. Water system. J. Glaciol., 35(119), 108-118.

Alley, R.B. 1989b. Water-pressure coupling of sliding and bed deformation: II. Velocity-depth profiles. J. Glaciol., 35(119), 119-129.

Alley, R.B. and C.R. Bentley. 1988. Ice-core analysis on the Siple Coast of West Antarctica. Ann. Glaciol., 11, 1-7.

Alley, R.B., D.D. Blankenship, C.R. Bentley, and S.T Rooney. 1986. Deformation of till beneath Ice Stream B, West Antarctica. Nature, 322(6074), 57-59.

Alley R.B., D.D. Blankenship, S.T. Rooney, and C.R Bentley. 1987a. Continuous till deformation beneath ice sheets. International Association of Hydrological Sciences Publication 170 (Symposium at Vancouver 1987 - The Physical Basis of Ice Sheet Modelling), 81-91.

Alley, R.B., D.D. Blankenship, C.R. Bentley, and S.T Rooney. 1987b. Till beneath Ice Stream B. 3. Till deformation: evidence and implications. J. Geophys. Res., 92(B9), 8921-8929.

Alley, R.B., D.D. Blankenship, S.T. Rooney, and C.R. Bentley. 1987c. Till beneath Ice Stream B. 4. A coupled ice-till flow model. J. Geophys. Res., 92(B9), 8931-8940.

Alley, R.B., D.D. Blankenship, S.T. Rooney, and C.R. Bentley. 1989. Sedimentation beneath ice shelves - the view from Ice Stream B. Mar. Geol., 85(2/4), 101-120.

Anderson, J.B., D.D. Kurtz, E.W. Domack, and K.M. Balshaw. 1980. Glacial and glacial marine sediments of the Antarctic continental shelf. J. Geol., 88(4), 399-414.

Barrett, P.J. 1975. Textural characteristics of Cenozoic preglacial and glacial sediments at Site 270 , Ross Sea, Antarctica. Initial Reports of the Deep Sea Drilling Project, 28, 757-767.
Bentley, C.R. 1987. Antarctic ice streams: a review. $J$. Geophys. Res., 92(B9), 8843-8858.

Bentley, C.R., and 6 others. 1987. Remote sensing of the Ross ice streams and adjacent Ross Ice Shelf, Antarctica. Ann. Glaciol., 9, 20-29.

Bindschadler, R.A., S.N. Stephenson, D.R. MacAyeal, and S Shabtaie. 1987. Ice dynamics at the mouth of Ice Stream B, Antarctica. J. Geophys. Res., 92(B9), 8885-8894.

Blankenship, D.D., C.R. Bentley, S.T. Rooney, and R.B. Alley. 1986. Seismic measurements reveal a saturated porous layer beneath an active Antarctic ice stream. Nature, 322(6074), 54-57.

Blankenship, D.D., C.R. Bentley, S.T. Rooney, and R.B Alley, 1987. Till beneath Ice Stream B. 1. Properties derived from seismic travel times. J. Geophys. Res., 92(B9), 8903-8911.

Blankenship, D.D., S.T. Rooney, R.B. Alley, and C.R. Bentley. 1989. Seismic evidence for a thin basal layer at a second location on Ice Stream B, Antarctica. (Abstract.) Ann. Glaciol., 12, 200.

Boulton, G.S. 1979. Processes of glacier erosion on different substrata. J. Glaciol., 23(89), 15-38.

Boulton, G.S. and R.C.A. Hindmarsh. 1987. Sediment deformation beneath glaciers: rheology and geological consequences. I. Geophys. Res., 92(B9), 9059-9082.

Brown, N.E., B. Hallet, and D.B. Booth. 1987. Rapid soft bed sliding of the Puget glacial lobe. J. Geophys. Res., 92(B9), 8985-8997.

Budd, W.F. and D. Jenssen. 1987. Numerical modelling of the large scale basal water flux under the West Antarctic ice sheet. In Van der Veen, C.J. and J. Oerlemans, eds. Dynamics of the West Antarctic ice sheet. Proceedings of a Workshop held in Utrecht, May 6-8, 1985. Dordrecht, etc., D. Reidel Publishing Company, 293-320.

Clarke, G.K.C. 1987. Subglacial till: a physical framework for its properties and processes. J. Geophys. Res., 92(B9), 9023-9036.

Engelhardt, H.F., W.D. Harrison, and B. Kamb. 1978. Basal sliding and conditions at the glacier bed as revealed by bore-hole photography. J. Glaciol., 20(84), 469-508.

Fahnestock, M. and N. Humphrey. 1988. Borehole water level measurements, Columbia Glacier, AK. [Abstract.] Ice, 86, 25-26.

Hampton, M.A. 1979. Buoyancy in debris flows. $J$. Sediment. Petrol., 49(3), 753-758.

Karl, H.A., E. Reimitz, and B.D. Edwards. 1987. Extent and nature of Ross Sea unconformity in western Ross Sea, Antarctica. In Cooper, A.K. and F.J. Davey, eds. The Antarctic continental margin: geology and geophysics of the western Ross Sea. Houston, TX, Circum-Pacific Council for Energy and Mineral Resources, 77-92. (Earth Science Series, 5B.)

Lingle, C.S. and T.J. Brown. 1987. A subglacial aquifer bed model and water pressure dependent basal sliding relationship for a West Antarctic ice stream. In Van der Veen, C.J. and J. Oerlemans, eds. Dynamics of the West Antarctic ice sheet. Proceedings of a Workshop held in Utrecht, May 6-8, 1985. Dordrecht, etc., D. Reidel Publishing Company, 249-285.

MacAyeal, D.R. In press. Ice flow over a deformable bed: theory and application to Ice Stream B, Antarctica. $J$. Geophys. Res.

MacAyeal, D.R., R.A. Bindschadler, S. Shabtaie, S. Stephenson, and C.R. Bentley. 1987. Force, mass, and energy budgets of the Crary Ice Rise complex, Antarctica. J. Glaciol., 33(114), 218-230.

Meier, M.F. 1989. Relationship between water input, basal water pressure, and sliding of Columbia Glacier, Alaska, U.S.A. (Abstract.) Ann. Glaciol., 12, 214-215.

Rodine, J.D. and A.M. Johnson. 1976. The ability of debris, heavily freighted with coarse clastic materials, to flow on gentle slopes. Sedimentology, 23, 213-234.

Rooney, S.T. Unpublished. Subglacial geology of Ice Stream B. (Ph.D. thesis, University of Wisconsin-Madison, 1988.)

Rooney, S.T., D.D. Blankenship, and C.R. Bentley. 1987a. Seismic refraction measurements of crustal structure in West Antarctica. In McKenzie, G.D., ed. Gondwana Six: Structure, Tectonics, and Geophysics. Washington, DC, American Geophysical Union, 1-7. (Geophys. Monogr. 40.) 
Rooney, S.T., D.D. Blankenship, R.B. Alley, and C.R. Bentley. 1987b. Till beneath Ice Stream B. 2. Structure and continuity. J. Geophys. Res., 92(B9), 8913-8920.

Rooney, S.T., D.D. Blankenship, R.B. Alley, and C.R. Bentley. 1988. Seismic-reflection profiling of a widespread till beneath Ice Stream B, West Antarctica. (Abstract.) Ann. Glaciol., 11, 210.

Rooney, S.T., D.D. Blankenship, R.B. Alley, and C.R. Bentley. In press. Seismic-reflection profiling of a sediment-filled graben beneath Ice Stream B, West Antarctica. Proceedings of Fifth International Sympasium on Antarctic Earth Sciences, Cambridge, 1987.

Shabtaie, S. and C.R. Bentley. 1987. West Antarctic ice streams draining into the Ross Ice Shelf: configuration and mass balance. J. Geophys. Res., 92(B2), 1311-1336.

Shabtaie, S., I.M. Whillans, and C.R. Bentley. 1987. The morphology of ice streams $A, B$, and $C$, West Antarctica, and their environs. J, Geophys. Res., 92(B9), 8865-8883.

Shoemaker, E.M. 1986. Subglacial hydrology for an ice sheet resting on a deformable aquifer. J. Glaciol., 32(110), 20-30. Sugden, D.E. and B.S. John. 1976. Glaciers and landscape: a geomorphological approach. London, Edward Arnold.

Van der Veen, C.J. and I.M. Whillans. 1989. Force budget: I, Theory and numerical methods. J. Glaciol., 35(119), 53-60.

Weertman, J. 1964. The theory of glacier sliding. J. Glaciol., $5(39), 287-303$.

Weertman, J. 1969. Water lubrication mechanism of glacier surges. Can. J, Earth Sci., 6(4, Pt. 2), 929-939.

Weertman, J. 1972. General theory of water flow at the base of a glacier or ice sheet. Rev. Geophys. Space Phys., 10(1), 287-333.

Weertman, J. and G.E. Birchfield. 1982. Subglacial water flow under ice streams and West Antarctic ice-sheet stability. Ann. Glaciol., 3, 316-320.

Whillans, I.M., J. Bolzan, and S. Shabtaie. 1987. Velocity of ice streams $\mathrm{B}$ and $\mathrm{C}$, Antarctica. J. Geophys. Res., 92(B9), 8895-8902. 